\title{
Microdosing: safer clinical trials and fewer animal tests
}

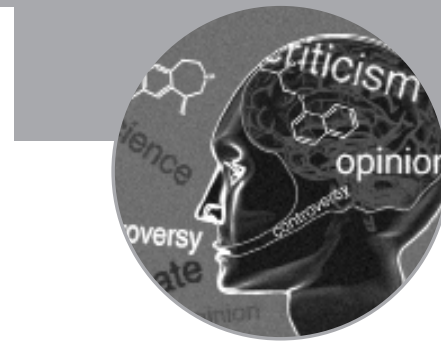

\footnotetext{
"The wider use of human microdosing would minimize all these animal tests ... by providing human-specific ADME data and, thus, identifying early those compounds destined to fail later owing to suboptimal pharmacokinetics or metabolism."
}

Human microdosing belongs to the group of new, advanced experimental approaches that meet 21st Century requirements. As suggested by the Centre for Medicines Research, without a new generation of product-development tools, it will be difficult to improve the 20 -year low in the number of new medical therapies launched onto the market [1], despite more investment in biomedical research worldwide over the last two decades.

As mentioned in the 'critical path' report published by the US FDA [101], 92\% of compounds that pass animal tests fail in Phase I clinical trials. A technique such as microdosing, which provides early data about the behavior of drugs in humans at very low doses, can only improve predictions of drug toxicity and efficacy, whilst also reducing the resources spent and the number of animal tests carried out.

In streamlining the drug-development process, human microdosing is also likely to reduce animal testing, a responsibility shared by companies, regulators and individual scientists worldwide. Legislation in Europe requires the Replacement, Reduction and Refinement (the 'Three Rs') of animal experiments wherever possible [2]. Similar policies are implemented in many countries, including the USA.

In the EU, the Commission and the member states also have a legislative duty to encourage research into methods that could achieve equivalent objectives, but using fewer animals or none at all. The European Centre for the Validation of Alternative Methods (ECVAM) was established in 1992 for this reason and, since then, some 27 nonanimal models and assays have been scientifically validated as full or partial replacements for animal tests and 20 have gained regulatory approval [102].

More than 12.1 million animals were used in 2005 (latest available figures) in experiments in the EU, of which 528,189 were used for safety testing of pharmaceuticals [3]. As well as their use in studies of absorption, distribution, metabolism and excretion (ADME), animals are used to assess longer-term toxicities of pharmaceuticals, such as subchronic and chronic toxicity (67,651 animals in the EU in 2005), developmental and reproductive toxicity (49,026 animals) and carcinogenicity $(26,589)$. The wider use of human microdosing would minimize all these animal tests, which are conducted later in drug development, by providing humanspecific ADME data and, thus, identifying early those compounds destined to fail later owing to suboptimal pharmacokinetics or metabolism [4]. A $10 \%$ improvement in identifying failing candidates before classic clinical trials could also save US $\$ 100$ million in development costs per drug [5].

The British government's Animal Procedures Committee, which advises on animal experiments, recommended in its 2002 report on the use of primates that human microdosing should be further developed and resourced. The Committee recognised that microdosing has the potential to limit the use of primates in repeatdose toxicity tests, pharmacokinetics and safety pharmacology studies [6]. In 2008, repeat-dose tests alone (subacute, subchronic and chronic) involved 2346 primates in Britain [7].

In contrast to the fairly extensive animal data required prior to a Phase I trial, singledose rodent tests can be the primary support for microdose studies in humans and the European Medicines Agency recognizes that microdosing, among other kinds of exploratory clinical trials "can reduce overall animal use in drug development" [103].

The use of subpharmacological and subtherapeutic microdoses in early clinical studies also offers better protection for Phase I trial volunteers, without compromising the safety of microdose subjects. It has been suggested that a microdose study of TGN1412 might have prevented the tragedy that occurred in 2006, when Phase I trial subjects suffered life-threatening, unexpected side effects despite extensive preclinical tests on animals, including rhesus and cynomolgus monkeys.

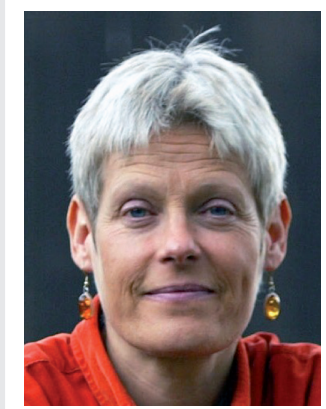

\section{Gill Langley}

Author for correspondence

Dr Hadwen Trust for

Humane Research, 18 Market

Place, Hitchin, Herts,

SG5 IDS, UK

Tel.: +44 I462 436819

Fax: +44 I462 436844

E-mail: sciencesources@

btinternet.com

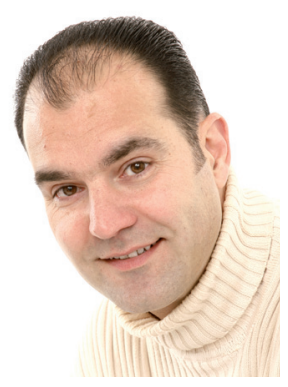

\section{Sebastien Farnaud}

Dr Hadwen Trust for

Humane Research, 18 Market

Place, Hitchin, Herts,

SG5 IDS, UK

Tel.: +44 I462436819

Fax: +44 I462 436844

E-mail: sebastien@

drhadwentrust.org 


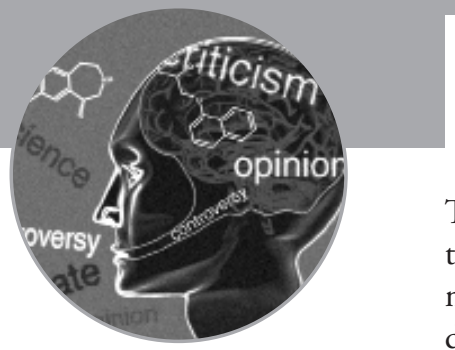

TGN1412 targets the CD28 receptor on T-cells, where there are differences between the rhesus monkey and human sequences. A microdose study with TGN1412, by systemic or dermal application, could have determined the amount of the antibody that bound to $\mathrm{T}$ cells in the whole human body without risk to the subjects, as well as providing pharmacokinetic and metabolic data relevant to the human species [8]. Safely obtained human microdose data may have been able to improve the design of the Phase I study.

In fact, the Duff report on the TGN1412 incident stated that "the view that higher-risk agents should be given at specified low dose levels, for example in the microgram or nanogram range ('microdosing' and 'nanodosing') may have value as a general guideline" [104].

The human relevance of microdosing applies to a wider field than drug toxicology, as illustrated by its proposed uses in oncology. For example, applying microdosing to measure interindividual variability in drug disposition caused by genetic and environmental factors is a promising application [9]. In addition, microdosing offers opportunities to conduct new study designs and investigate previously unanswerable questions in oncology [10].

The value of microdosing in other sectors has already been recognized. As a case in point, microdosing was considered by an ECVAM expert group as a potential replacement for most of the toxicokinetic and ADME data normally obtained from animal tests for chemicals used in cosmetics [11].

\section{The role of nonanimal techniques}

Many researchers, governments and regulators now agree that replacement techniques are often more relevant, reliable, sensitive, costeffective and reproducible than experiments on animals [105]. The FDA's report stated that a major problem is the failure to create and use novel tools to deliver "fundamentally better answers about how the safety and effectiveness of new products can be demonstrated, in faster time frames, with more certainty, and at lower costs" [101].

The FDA called for a greater emphasis on in vitro, clinical and computational tools. For example, using human cell lines to characterize drug metabolic pathways can predict human metabolism and help eliminate compounds with unfavorable metabolic profiles. This approach has meant that clinical failures due to druginteraction problems are now far less likely.
Computational modeling is increasingly being applied to human disease simulation, to predict novel drug pharmacokinetics and to conduct 'virtual' clinical trials. In terms of ADME simulation, the mathematical relationship between drug doses, plasma concentrations, pharmacokinetics and pharmacodynamics can be characterized and patient covariates are included in the computational model. The systematic application of mathematical modeling could significantly improve drug development.

Analytical techniques have already replaced many animal tests and in so doing have improved sensitivity, reliability and precision [12]. For example, digitalis was once routinely tested for potency on guinea pigs and pigeons using a lethal method. In the late 1980s, this was replaced by a chemical colorimetric assay which directly measured the content of digitoxin. In 1980, insulin batch testing used 600 mice per test, but was later replaced by HPLC - a more rapid and precise method [13].

\section{Where now?}

The number of consortia and organizations working to replace animal tests in medicines development is growing fast. The European Partnership to Promote Alternative Approaches to Animal Testing was established in 2005 as a joint initiative between the European Commission, European trade associations from seven industry sectors (including pharmaceuticals) and individual companies. Its purpose is to promote the development and implementation of modern Three $\mathrm{R}$ approaches, including nonanimal methods, in the field of safety testing [106].

In 2009, an international memorandum of co-operation was signed by four agencies, in the USA, Japan, Canada and the EU, to co-ordinate the adoption of nonanimal testing methods. The agreement "will speed the adoption of new test methods based on advances in science and technology. Animal welfare will also be improved by the national and international acceptance of alternative test methods that reduce, refine and replace the use of animals", according to William Stokes, an assistant surgeon general in the US Public Health Service and a leading scientist in the Three Rs field [107].

Although nonlinear absorption or disposition characteristics could affect the validity of microdose predictions of therapeutic-level pharmacokinetics, recent publications suggest that a concordance of approximately $80 \%$ can be anticipated [14]. Its direct and safe applications for humans, together with its economical and ethical benefits, bring microdosing to the 
forefront of 21st Century technology. Combining human microdosing with other complementary nonanimal approaches clearly offers ethical, scientific and efficiency benefits for pharmaceutical development. Wider recognition of this should lead to faster progress towards that goal.

\section{Financial \& competing interests disclosure} Both authors are employed by the Dr Hadwen Trust for Humane Research (Registered Charity No 261096), the $U K$ 's leading medical research charity exclusively funding nonanimal research techniques to replace animal experiments, benefiting people and animals. The authors have no other relevant affliations or financial involvement with any organization or entity with a financial interest in or financial conflict with the subject matter or materials discussed in the manuscript. This includes employment, consultancies, honoraria, stock ownership or options, expert testimony, grants or patents received or pending, or royalties.

No writing assistance was utilized in the production of this manuscript.

\section{Bibliography}

1 Centre for Medicines Research International. International Pharmaceutical R\&D Factbook. Thomson Reuters (2009).

2 Council Directive 86/609/EEC of 24 November 1986 on the approximation of laws, regulations and administrative provisions of the Member States regarding the protection of animals used for experimental and other purposes. Off. J. Eur. Comm. L358, 1-29 (1986).

3 Commission of the European Communities, Brussels, 5.11.2007. $\operatorname{COM}(2007) 675$ final. Fifth Report on the Statistics on the Number of Animals used for Experimental and other Scientific Purposes in the Member States of the European Union \{SEC(2007)1455\}.

4 Combes RD, Berridge T, Connelly J et al. Early microdose studies in human volunteers can minimise animal testing: proceedings of a workshop organised by volunteers in research and testing. Eur. J. Pharmacol. Sci. 19, 1-11 (2003).

5 Boston Consulting Group. A revolution in $\mathrm{R} \& \mathrm{D}$ - how genomics and genetics will affect drug development costs and times. In: Parexel Pharmaceutical R\&D Statistical Sourcebook. (2002/2003).

6 Animal Procedures Committee. The use of primates under the Animals (Scientific Procedures) Act (1986): analysis of current trends with particular reference to regulatory toxicology. (2002).

7 Home Office. Statistics of Scientific Procedures on Living Animals Great Britain 2008. HC 800. The Stationery Office, London, UK (2009).
8 Focus on Alternatives. Submission to the Expert Working Group studying the TGN1412 incident. Appendix to Bhogal N and Combes R. An update on TGN1412. ATLA 34, 351-356 (2006).

9 Deeken JF, Figg WD, Bates SE, Sparreboom A. Toward individualized treatment: prediction of anticancer drug disposition and toxicity with pharmacogenetics. Anticancer Drugs 18, 111-126 (2007)

10 Sparreboom A. Unexplored pharmacokinetic opportunities with microdosing in oncology. Clin. Cancer Res. 13, 4033-4034 (2007).

11 Coecke S, Blaauboer BJ, Elaut G et al. Toxicokinetics and metabolism. In: Alternative (Nonanimal) Methods for Cosmetics Testing: Current Status and Future Prospects. A Report Prepared in the Context of the 7th Amendment of the Cosmetics Directive. ATLA. 33(Suppl. 1), 147-175 (2005).

12 Langley G, Evans T, Holgate ST, Jones A. Replacing animal experiments: choices, chances and challenges. Bioessays 29, 918-926 (2007).

13 Anonymous. Reduction of the use of animals in the development and control of biological products. Lancet 2, 900-902 (1985).

14 Lappin G, Garner C. The utility of microdosing over the past 5 years. Exp. Opin. Drug Metab. Toxicol. 4, 1499-1506 (2008).

\section{- Websites}

101 US FDA, US Department of Health and Human Services. Challenge and Opportunity on the Critical Path to New Medical Products. (2006)
www.fda.gov/downloads/ScienceResearch/ SpecialTopics/CriticalPathInitiative/ CriticalPathOpportunitiesReports/ UCM077254.pdf

102 Tracking system for alternative test methods review, validation and approval in the context of EU regulations on chemicals http://tsar.jrc.ec.europa.eu

103 European Medicines Agency. Note for guidance on non-clinical safety studies for the conduct of human clinical trials and marketing authorization for pharmaceuticals (CPMP/ICH/286/95) (2009) www.ema.europa.eu/pdfs/human/ ich/028695en.pdf

104 Expert Scientific Group on Phase One Clinical Trials, Final Report, 30 November 2006. The Stationery Office, London, UK, (2006) www.dh.gov.uk/

105 The Government Reply to the Report of the House of Lords Select Committee on Animals in Scientific Procedures. Session 2001-2002. Presented to Parliament by the Secretary of State for the Home Department. 4, 7 January 2003 (Cm. 5729)

www.archive2.official-documents.co.uk/ document/cm57/5729/5729.pdf

106 European Partnership for Alternative Approaches to Animal Testing http://ec.europa.eu/enterprise/epaa

107 NIH. Countries unite to reduce animal use in product toxicity testing worldwide. News release. 27 April 2009 www.nih.gov/news/health/apr2009/ niehs-27.htm 